\title{
MODIFICATION OF CATALYTIC CONVERTER USING ZEOLITE BASED COATING MATERIAL FOR EXHAUST SYSTEM
}

\author{
Gurusiddayya ${ }^{1}$, Shaktivelu. $M^{2}$, Radha $\mathbf{H ~ R}^{3}$, Lingaraju.L ${ }^{4}$ \\ ${ }^{I}$ Assistant Professor, Department of Mechanical Engineering, T.John Institute of Technology, Karnataka, India \\ ${ }^{2}$ Professor, Department of Mechanical Engineering, T.John Institute of Technology, Karnataka, India \\ ${ }^{3}$ Professor, Department of Chemistry, T.John Institute of Technology, Karnataka, India \\ ${ }^{4}$ Assistant Professor, Department of Mechanical Engineering, T.John Institute of Technology, Karnataka, India
}

\begin{abstract}
Now a days there is a tremendous change in the climatic conditions due to global warming and greenhouse gases results in the floods, draughts and famine. More usage of petrol \& diesel in vehicles, leads to poisonous gases enters into atmosphere results in environment become hazardous. Carbon Dioxide is one of the major components of Greenhouse gases which results in greenhouse effect. More amount of Carbon Dioxide releases from burning of petroleum based products which are emitting from the Vehicles and Industries. For the control of the emission of the carbon dioxide into the atmosphere we have chosen for adsorption of Carbon Dioxide from the exhaust of the gasoline vehicles using Zeolite. The gasoline vehicle used for testing is following the EURO - V emission norms and the Carbon Dioxide content releasing from the vehicle is reduced by more than $25 \%$.
\end{abstract}

Keywords: Exhaust, Zeolite, Carbon Dioxide

\section{INTRODUCTION TO EXHAUST SYSTEM}

An exhaust system is usually piping used to guide reaction or burnt exhaust gases away from a controlled combustion inside an engine or stove. The entire system carries burnt gases from the engine and provided with one or more exhaust pipes. Depending on the entire system design, the exhaust gas may travels through one or more of:

I. Cylinder head and exhaust manifold

II. A turbocharger to increase engine power.

III. A catalytic converter to reduce air pollution.

IV. A muffler (North America) / silencer (UK/India), to reduce noise

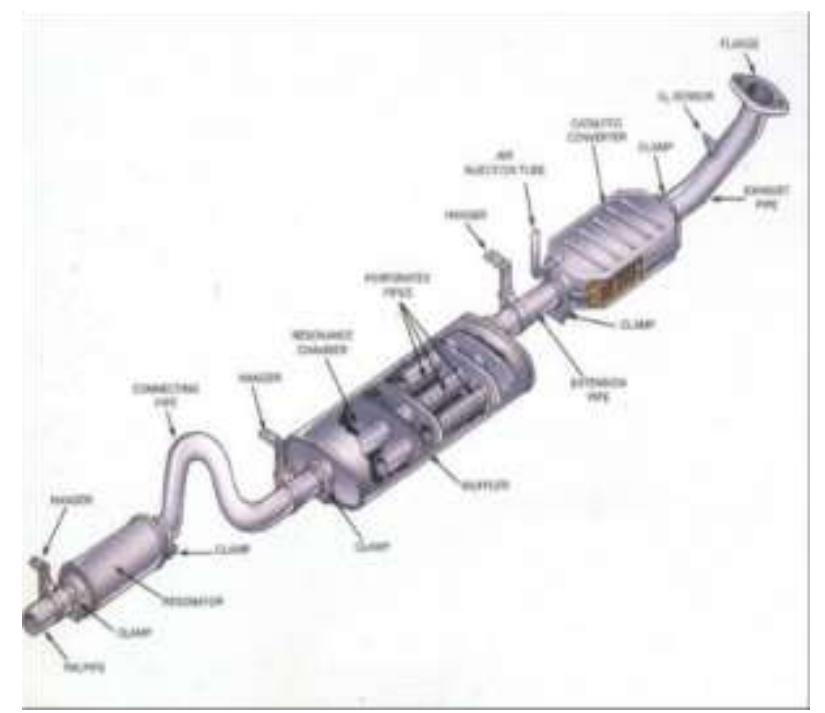

Fig 1: Exhaust System
The exhaust system starts with manifolds on the engine and terminates with the tail pipe. Basically, it consists of an exhaust manifold, heat riser, exhaust pipe, catalytic converter, muffler, resonator, and tail pipe. Following is a closer look at each component.

\section{Parts of an Exhaust System}

$\begin{array}{ll}\text { a) } & \text { Exhaust Manifold } \\ \text { b) } & \text { Flange and Clamp } \\ \text { c) } & \text { Catalytic Converter } \\ \text { d) } & \text { Muffler } \\ \text { e) } & \text { Connecting Pipe } \\ \text { f) } & \text { Resonator } \\ \text { g) } & \text { Tail Pipe }\end{array}$

\subsection{Exhaust Manifold}

In automotive engineering, an exhaust manifold collects the exhaust gases from multiple cylinders into one pipe .The exhaust manifold collects the burned gases as they are expelled from the engine cylinders and directs them to the exhaust pipe. Exhaust manifolds are used to collect engine burnt gases from multiple cylinders \& bunt gases delivers into exhaust \& made from cast iron or stainless steel.

\subsection{Flange and Clamp}

Flange and clamp are used to connect the exhaust pipe from exhaust manifold to catalytic convertor. A flange is a plate or ring which is used to form a rim at the end of a pipe when fastened to the pipe to prevent leakage and for easy flow of gases through it. A clamp is a tightening device used to 
secure objects tightly together to avoid the movement or separation through the application of back pressure.

\subsection{Catalytic Converter}

To follow stricter emission control standards, manufacturers began to include catalytic converters on domestic automobiles. Located between the exhaust pipe and muffler, this device converts harmful carbon monoxide and hydrocarbons into carbon dioxide and water vapour. Many converters also change nitrogen oxides into harmless oxygen and nitrogen. The function of catalytic converter is to treat the exhaust gas to convert harmful pollutant into harmless gases. All exhaust gases must pass through catalytic converter which is located in the exhaust system.

The catalytic converter consists of a material called catalyst which causes a chemical change without entering into chemical reaction. It makes two chemical ta react with each other and hence reduce amount of $\mathrm{HC}, \mathrm{CO}$, and $\mathrm{NO}_{\mathrm{X}}$ in the exhaust gases.

It consists of two different catalysts, one to treat $\mathrm{HC}$ and $\mathrm{CO}$ and other to treat $\mathrm{NO}_{\mathrm{x}}$. The first catalyst promotes $\mathrm{HC}$ to unite with $\mathrm{O}_{2}$ to produce $\mathrm{H}_{2} \mathrm{O}$ and $\mathrm{CO}_{2}$. The second catalyst promotes $\mathrm{CO}$ to react with $\mathrm{O}_{2}$ and hence to release $\mathrm{CO}_{2}$. As this converter oxidizes $\mathrm{HC}$ and $\mathrm{CO}_{2}$, it is known as oxidizing converter. The platinum and palladium are used as oxidizing catalysts. The catalyst used for $\mathrm{NO}_{\mathrm{X}}$ splits $\mathrm{O}_{2}$ and $\mathrm{N}_{2}$ and hence $\mathrm{NO}_{\mathrm{X}}$ becomes harmless $\mathrm{N}_{2}$ and $\mathrm{O}_{2}$. The converter is known as reducing converter and metal rhodium is used for this purpose. A large surface area of catalytic converter is coated with catalyst. The coated surface area or substrate is in the form of a bed of small beads or pellets or a ceramic honey comb. Usually honeycomb converter is round and pellet type converter is flat.

The vehicles fitted with catalytic converter in the exhaust system must be unleaded gasoline, otherwise lead in the gasoline coats the catalyst and makes the converter in effective. The air fuel ratio for the mixture must be stoichiometric ratio for effective working of the catalyst converter.

\subsection{Muffler}

The muffler lowers noise through the use of perforated tubes and baffles that permit the exhaust gases to expand into the area between the tubes and the outer shell of the muffler. This gas distribution slows and cools the exhaust gas flow, thus reducing sound without disturbing the flow of gases.

\subsection{Connecting Pipe}

It is used to connect the muffler to the resonator.

\subsection{Resonator}

A resonator is a secondary muffler designed to reduce sound level even further. It is usually found on a vehicle having a long wheelbase and a high-performance engine. It can be mounted in front of or behind the muffler.

\subsection{Tail Pipe}

It is the hose through which exhaust gases emerges out from the system to atmosphere. The diameter of this tail pipe usually varies from 1-8 inch.

\section{WASH COATING OF MESH}

\subsection{Preparation of Zeolite Mesh}

For the preparation of the zeolite mesh a steel mesh of $4 \times 4$ inch is chosen and it is subjected to preliminary cleaning process.

\subsection{Cleaning of Mesh}

Initially the mesh is cleaned with $10 \%$ of $\mathrm{Hcl}$ which is a solute in the solution and solvent being $300 \mathrm{ml}$ of distilled water. Acetone solution is used to dry the mesh for using it at a quantity of $30 \mathrm{ml}$.

\subsection{Preparation of Zeolite slurry}

Finally the Zeolite Mesh is prepared by immersing into the zeolite slurry and it is allowed to absorb the zeolite particles by keeping it immersed into a period of around $20 \mathrm{hrs}$.

Then the mesh is let to drying process by keeping the same in a muffler furnace for around 10mins at a temperature of 100degree Celsius.

The deposits at the corners have to be removed as they may interfere the reaction process happening between the catalyst and the exhaust gases, and for the same the zeolite mesh is exposed to a hot blower and it is made sure that the deposits are removed permanently, so that the exhaust gas velocity is not obstructed as mentioned above.

Zeolite slurry is prepared by mixing $200 \mathrm{gms}$ of natural zeolite (ZSM-5) which is in powder format with distilled water with a quantity of $3000 \mathrm{ml}$.

Fig:Preparation of Zeolite slurry

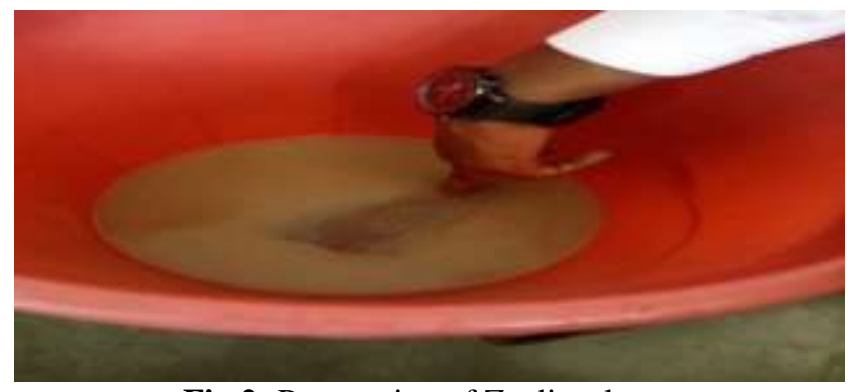

Fig 2: Preparation of Zeolite slurry 
The results of $\mathrm{CO}_{2}$ absorption before and after the reactor chamber containing catalyst used with various engine speeds in zero load conditions.

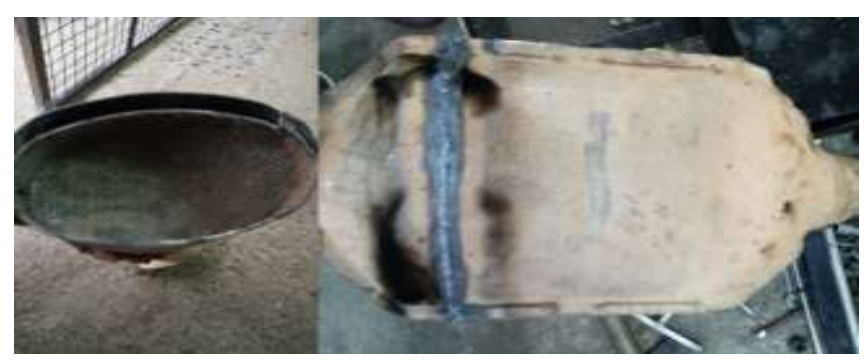

Fig 3: Modified Catalytic Converter

\section{EMISSION TEST RESULTS}

Table 1: Experimentation \&Tabulation

\begin{tabular}{|l|l|l|l|l|}
\hline Condition & RPM & $\begin{array}{l}\mathrm{CO} 2 \\
\mathrm{ppm}\end{array}$ & $\begin{array}{l}\text { Difference } \\
\text { Between Before } \\
\text { and After } \\
\text { Reduction }\end{array}$ & $\begin{array}{l}\text { Rercentage } \\
(\%)\end{array}$ \\
\hline Before & 1000 & 4.83 & 0.79 & 16.657 \\
\hline After & 1000 & 4.04 & 0.79 & \\
\hline
\end{tabular}

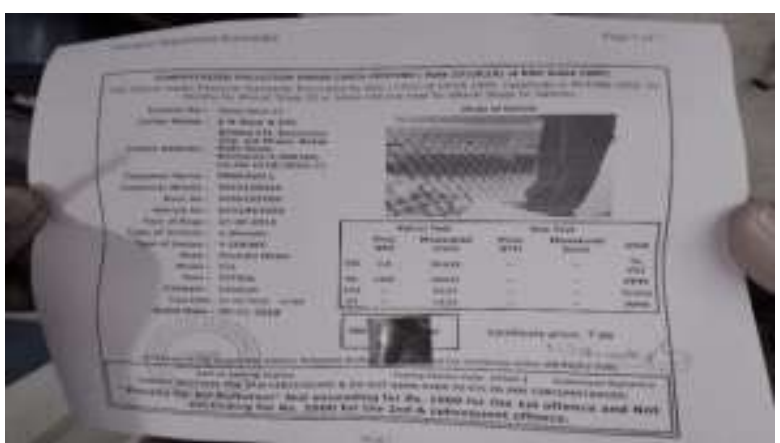

Fig 4: Before Implementing the Modified Converter

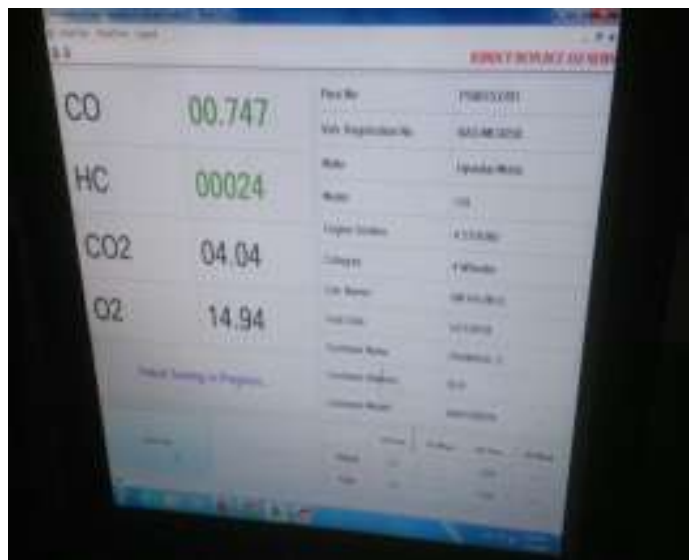

Fig 5: After implementing

\section{CONCLUSION}

From the results, the paper concludes that the emission of Carbon dioxide from the vehicle is reduced by maximum of $16.657 \%$ and apart from the reduction of carbon dioxide emission some amount of Hydrocarbons has been reduced.
This process of adsorption won't affect the increase in emission of other gases. The Recycling of catalyst leads to the adsorption of carbon dioxide it will not harmful to the environment. In future a complete product can be built and its mass production cost will be low.

\section{REFERENCES}

[1] Mylaudy Dr. Rajadurai.et. al. International Journal of Engineering Research and Applications ISSN: 2248-9622, Vol. 6, Issue 5, May 2016, pp.73-77.

[2] Aimaro Sanna et al. "Waste materials for carbon capture and storage by mineralisation A UK perspective" Applied Energy 99 (2012) 545-554.

[3] S. Jenoris. Muthiya et al. "Carbon Capture and storage from automobile exhaust to reduce co2 emission", ISSN - 2319-8753, IJIRSET. Vol - 3, Issue-2, April-14 [4] Minh T. Ho. et al. "Reducing the Cost of $\mathrm{CO} 2$ Capture from Flue Gases Using Membrane Technology", Ind. Eng. Chem. Res. 2008, 47, 1562-1568.

[4] A.F. Cronstedt, Kongl Vetenskaps Academiens Handlingar Stockholm, 17, 1756, p. 120.

[5] Rollmann, L. D.; Valyocsik, E. W.(1995).Zeolite Molecular Sieves. Inorganic Syntheses. Inorganic Syntheses. 30. pp. 227-234. 